\title{
International Symposium on Composers of African \& Afro-Caribbean Descent: Veni, Vidi, Vici.
}

\section{Paul Shaw University of Minnesota ${ }^{1}$}

\section{THEY CAME}

Sharing a history similar to that of its Caribbean neighbours, yet endowed with greater economic and logistic liquidity, Nassau, The Bahamas' capital city (on the island of New Providence), seemed the best venue for the first International Symposium on Composers of African \& Afro-Caribbean Descent, held on February 21, 2013. New York-based orchestral conductor, Marlon Daniel, with his Ensemble du Monde in tow (courtesy of the Nassau Music Society), and enterprising flutist Christine Gangelhoff, Assistant Professor of Music at the College of The Bahamas (where the symposium was held), was the organizer. Participants came from the United States, Great Britain, Jamaica, Puerto Rico, Trinidad and The Bahamas.

\section{THEY SAW ... AND HEARD}

As Caribbean art music is a relatively unheralded field, the composers deserve particular mention:

Cleophas Adderley - The Bahamas

Peter Ashbourne - Jamaica

Carlos Carrillo-Cotto - Puerto Rico/United States
Christian Justilien - The Bahamas

Dominique Le Gendre - Trinidad and Tobago/Great Britain

Khyle Quincy Parker - The Bahamas

Paul Shaw - Jamaica/United States

Adam Walters - Great Britain/Trinidad and Tobago

Audrey Dean-Wright - The Bahamas

A day-long discussion (divided into three sessions, with the first two moderated by Edward Bethel and Nicolette Bethel-the offspring of E. Clement Bethel, arguably the Bahamas' foremost composer of art music) that included samples of various works, both live and recorded, revealed a wide range of styles espousing everything from folk to posttonal idioms. K. Quincy Parker, moderator of the third session entitled "Diversity in Classical Music", noted that regardless of style there were touches of an underlying syncopated rhythm traceable to West Africa in just about every selection. Two large works in progress, Dominique Le Gendre's "Jab Molassie", a distinctively Trinidadian theatre piece inspired by Igor Stravinsky's "A Soldier's Tale", and Peter Ashbourne's reggae opera, "Mikey", are striking examples of Old

\footnotetext{
${ }^{1}$ Paul Shaw, School of Music, University of Minnesota, 100 Ferg Hall, 2106 4th Street S. Minneapolis, MN, 55455

E-mail: shawx004@umn.edu

APA reference: Shaw, P. (2013). International Symposium on Composers of African and AfroCaribbean descent: Veni, vidi, vici. The International Journal of Bahamian Studies, 19(2), 77-78. https:// doi.org/10.15362/ijbs.v19i2.188
} 
World genres finding a renaissance in the New World. The Symposium attendees all look forward to their world premieres with great expectations.

Interestingly coupled with the International Symposium on Composers of African \& Afro-Caribbean Descent was a festival of six concerts. The concerts showcased Ensemble du Monde (with guest soloist Koh Gabriel Kameda, violin, under the direction of Maestro Marlon Daniel); Quartet-inResidence Quatuor Mahogany (Anyango Yarbo-Davenport, violin; Shelby Yamin, violin; Tia Allen, viola; and Tahirah Whittington, violoncello); C Force (Christine Gangelhoff, flute; Christian Justilien, euphonium; and Christy Lee, piano); and the Bahamas National Youth Choir (under the direction of its founder, Cleophas R. E. Adderley). One of the festival's world premieres, "Riff for Strings and Percussion" by Dominique Le Gendre (performed by Quatuor Mahogany and Gillard Louis-a student at The College of the Bahamas-who nimbly played the snare drum), exists in an essentially tonal landscape and marches with the hope and determination of taking flight. In one sense, it stands as a metaphor for "Le Génie Humain", the festival's other Le Gendre world premiere. The former peters out after establishing a driving ostinato, then resumes with darker timbres rising to an abrupt, short-lived climax, more human than genius. Yet, there is a lingering awareness of the experience. Perhaps, to strive is human; to achieve, indign.

The major selling point of the festival was the music of Joseph Bologne, Le Chevalier de
Saint-Georges (1745-1799), "The Black Mozart", championed at the festival by Maestro Daniel, Artistic Director of the SaintGeorges International Festival in Boulogne's native Guadeloupe. Seeming more innocent at first than his more famous European contemporary, Saint-Georges, particularly in his "Violin Concerto in D Major, Op. 2, No. 2", takes some unexpected turns, employing an occasional whole-step appoggiatura and co-mingling baroque and classical figurations to great effect. Form, harmony and sensibility in this work, as well as in his "Overture to L'amant anonyme" and in his "Quartet in G minor, Op. 14, No. 6", are familiar, but the details are refreshingly individual.

\section{THEY CONQUERED}

Whether or not one ascribes truth to the Aesop fable, "The North Wind and the Sun", in which the Sun is able to affect the metaphorical disposition of The Traveler with warmth rather than bluster, it is my considered opinion that, in a similar manner, the events of February 20th-24th, 2013 conquered hearts. This became most powerfully evident for me when an unaffiliated patron from one of the most celebrated European centers of art music (who sat in the front row at every single concert) declared that the sincerity and emotional warmth of the Caribbean peoples and their concomitant culture had inspired a family relocation to The Bahamas. May the sun continue to shine on the creative efforts of all who made the inaugural International Symposium on Composers of African \& Afro-Caribbean Descent a reality. 